\title{
Efficiency of health resource utilisation in primary-level maternal and child health hospitals in Shanxi Province, China: a bootstrapping data envelopment analysis and truncated regression approach
}

Tao Zhang, Wei Lu* and Hongbing Tao

\begin{abstract}
Background: District- and county-level maternal and child health hospitals (MCHHs) are positioned to provide primary maternal and child healthcare in rural and urban areas of China. Their efficiencies and productivity largely affect the equity and accessibility of maternal and child health care. This study aimed to assess the efficiency of district- and county-level MCHHs in China and identify their associated factors.
\end{abstract}

Methods: Thirty-three district- and 84 county-level MCHHs were selected from Shanxi Province in 2017. At the first stage, bootstrapping data envelopment analysis (DEA) models were established to calculate the technical efficiency (TE), pure technical efficiency (PTE) and scale efficiency (SE) of district- and county-level hospitals. At the second stage, the estimated efficiency scores were regressed against external and internal hospital environmental factors by using bootstrap truncated regression to identify their determinants.

Results: The average TE, PTE and SE scores for district-level MCHHs were 0.7433, 0.8633 and 0.9335 , respectively. All hospitals were found to be weakly efficient, although more than $50 \%$ of the hospitals performed with efficient SE (SE scores $\geq 100 \%$ ). As for county-level MCHHs, their average TE, PTE and SE scores were 0.5483, 0.6081 and 0.9329, respectively. The hospitals with TE and PTE scores less than 0.7 accounted for more than 60\%, and no hospital was observed to operate effectively. Truncated regressions suggested that the proportion of health professionals, including doctors, nurses, pharmacists, inspection technician and image technician (district level: $\beta=0.57,95 \% \mathrm{Cl}=$ 0.30-0.85; county level: $\beta=0.33,95 \% \mathrm{Cl}=0.15-0.52$ ), and the number of health workers who received job training (district level: $\beta=0.67,95 \% \mathrm{Cl}=0.26-1.08$; county level: $\beta=0.34,95 \% \mathrm{Cl}=0.14-0.54$ ) had a positive association with efficiency scores. The amount of financial subsidy $(\beta=0.07,95 \% \mathrm{Cl}=0.05-0.09)$ was found to be directly proportional to the productive efficiency of the county-level MCHHs.

(Continued on next page)

\footnotetext{
* Correspondence: Tony12371@126.com

Department of Health Management, School of Medicine and Health

Management, Tongji Medical College, Huazhong University of Science and Technology, No.13, Aviation Road, Qiaokou District, Wuhan, Hubei Province, China
}

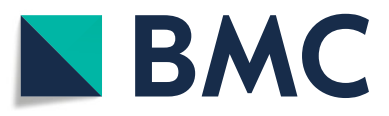

(c) The Author(s). 2020 Open Access This article is licensed under a Creative Commons Attribution 4.0 International License, which permits use, sharing, adaptation, distribution and reproduction in any medium or format, as long as you give appropriate credit to the original author(s) and the source, provide a link to the Creative Commons licence, and indicate if changes were made. The images or other third party material in this article are included in the article's Creative Commons licence, unless indicated otherwise in a credit line to the material. If material is not included in the article's Creative Commons licence and your intended use is not permitted by statutory regulation or exceeds the permitted use, you will need to obtain permission directly from the copyright holder. To view a copy of this licence, visit http://creativecommons.org/licenses/by/4.0/ The Creative Commons Public Domain Dedication waiver (http://creativecommons.org/publicdomain/zero/1.0/) applies to the data made available in this article, unless otherwise stated in a credit line to the data. 
(Continued from previous page)

Conclusion: The operational inefficiency of district- and county-level MCHHs in Shanxi Province is severe and needs to be substantially improved, especially in terms of TE and PTE. Hiring additional medical personnel and ensuring the stability of the workforce should be prioritised. The Chinese government must provide sufficient financial subsidy to compensate for service costs.

Keywords: China, Data envelopment analysis, Maternal and child health hospital, Technical efficiency, Truncated regression

\section{Background}

The health status of women and children directly reflect the level of national health and social development [1]. The number of women and children accounts for nearly two-thirds of the whole population in China, and maternal and child health care (MCHC) has always been the focus of government welfare programmes [2]. In the eight Millennium Development Goals (MDGs) advocated by the United Nations, two MDGs are directly related to MCHC: MDG 4 (a two-third reduction in under-5 mortality between 1990 and 2015) and MDG 5 (a three-quarter reduction in maternal mortality ratio between 1990 and 2015) [3]. Although the MDGs have come to the end of their term, a post-2015 agenda comprising 17 Sustainable Development Goals are implemented, in which the health and well-being of women and children are still two important goals [4]. Being a United Nations member, the Chinese government has launched the policy of 'China women and children development programme' every 10 years since 2001 with the aim of providing equitable and high-quality maternal and child care to protect their basic health rights [5].

China's one-child policy was replaced by a universal two-child policy (almost all Chinese people can have their preferred number of children) in 2015. Although several studies have indicated that this new policy is unlikely to cause a large increase in the average birth rate in China, some regions, such as rural areas and small towns, may face an increase in fertility due to an unbalanced development level across the country [6]. Therefore, the service capacity of $\mathrm{MCHHs}$ should be improved.

In recent years, the Chinese government has made huge investments in $\mathrm{MCHC}$, especially in terms of the physical facilities and human resources of maternal and child health hospitals (MCHHs). Predictably, these efforts have generated remarkable effects. For example, MDG 4, which aims to reduce child mortality by two-thirds, has been reached in advance of 9 years; MDG 5, which seeks to decrease maternal mortality by three-quarters, has been achieved 1 year ahead of schedule [7-9]. However, unequal and inefficient $\mathrm{MCHC}$ remains a persistent issue in China, and an $\mathrm{MCH}$ service network is lagging in the entire healthcare system [7].
The administrative divisions in China are divided into four levels: provincial, municipal, county/district and township levels. Accordingly, the MCHC system is composed of different levels of MCHHs. Given that MCHHs are absent at the township level in China, county- and district-level $\mathrm{MCHHs}$ are positioned to provide primary healthcare institutions. Although county- and districtlevel hospitals are classified at the same administrative level, they have different functions. County-level $\mathrm{MCHH}$ are located in rural regions and provide $\mathrm{MCH}$ services for rural residents. By contrast, district-level $\mathrm{MCHH}$ are located in urban regions and provide $\mathrm{MCH}$ services for urban residents [10]. However, the development of both county- and district-level MCHHs has been lagging due to a serious shortage in health resources, particularly in the number of professional health workers [11]. To address these problems, the Chinese government has allotted sufficient funds into the primary healthcare sector, including $\mathrm{MCHHs}$, since China's 2009 health system reform [12]. Therefore, whether these resources have been well utilised must be examined.

Previous studies that investigated the productive efficiency of MCHHs in China have provided insightful evidence. For instance, XU Yan et al. (2013) measured and evaluated the productive efficiency of 85 county-level $\mathrm{MCHHs}$ in Jiangsu Province and found that $58.8 \%$ of the hospitals have a low level of productive efficiency [13]. Xuan Wang et al. suggested that the overall operational efficiency of county-level MCHHs in Guangxi is low and needs to be substantially improved [10]. Other relevant studies found that the inefficiency of $\mathrm{MCHHs}$ greatly affects the quality and equality of $\mathrm{MCH}$ services [10, 14-16].

To date, existing literature has rarely scrutinised the productive efficiency of primary-level $\mathrm{MCHHs}$ after China's new round of healthcare system reforms and their multi-faceted influencing factors, although studies have closely examined the performance of $\mathrm{MCHHs}$ in terms of productive efficiency. The objectives of this study were to measure the productive efficiency of county- and district-level MCHHs and identify their associated factors from the perspectives of internal and external environments. We hope to provide appropriate 
strategies for the sustainable development of primarylevel MCHHs in China.

\section{Methods Study setting}

Shanxi Province, located in the central region of China, had a population of approximately 36 million in 2017, andthe female and children populations accounted for 48.1 and $15.5 \%$, respectively. Its per capita gross domestic product (GDP) was 40,557 Chinese Yuan in 2017, ranking it 26th amongst 31 provinces and municipalities in mainland China. A total of 134 provincial-, municipaland district-/county-level MCHHs provide healthcare services across the entire province.

\section{Data sources}

We adopted a census sampling approach to investigate 117 primary-level $\mathrm{MCHHs}$ (33 district-level and 84 county-level MCHHs) in Shanxi Province. The selfadministered questionnaire related to the input and output of MCHHs was distributed to managers in each hospital via e-mail, and all questionnaires were returned (response rate: 100\%) from June to August 2018. After checking the returned questionnaires for completeness, the data were inputted into the database. In addition, some information about the external hospital environment, such as population and GDP, was extracted from Shanxi Statistical Yearbook in 2017. No patient information was included in this study.

\section{Statistical analysis}

This study applied a two-stage analysis strategy: firstly, a bootstrapping data envelopment analysis (DEA) was used to measure productive efficiency of county- and district-level MCHHs. We then adopted bootstrap truncated regression to explore the factors associated with their productive efficiency.

\section{Stage one: a bootstrapping DEA}

DEA is widely used to examine the productive efficiency of health institutions around the world because it does not require assumptions on functional form and can be used for relative productive efficiency analysis with multiple inputs and outputs $[17,18]$. The DEA model comprises the CCR model (production is constant return to scale [CRS], where an increase in the input will result in a proportional increase in the output) and the $\mathrm{BCC}$ model (production is variable return to scale [VRS], which means that an increase in the input will result in either an increase or decrease in the output when units are not operating at optimum scale) [18]. Technical efficiency (TE) measured by the CCR model may be altered by scale efficiency (SE) [18]. VRS has two dimensions: increasing returns to scale (IRS), that is, increasing the input of one unit brings over one unit increase in outputs; and decreasing returns to scale (DRS), which indicates one unit increase in inputs will result in below one unit increase in output [19]. The BCC model calculates the pure technical efficiency (PTE) that incorporates the effect of SE $[18,20]$ :

$$
T E_{D E A-C R S}=P T E_{D E A-V R S} \times S E
$$

However, all decision-making unit (DMU) scores in the DEA model decrease in a fluctuating range when influenced by environmental and random factors. Thus, using traditional DEA to measure productive efficiency scores may generate bias [21]. To correct this bias, we introduced a bootstrapping technique by simulating the data-generating process to obtain a new estimate for each simulated sample [22]. The simulated data set is approximately equivalent to the original one, which means that the sampling distributions and standard deviations are close to the original ones. The productive efficiency scores estimated via bootstrapping DEA can produce bias-corrected productive efficiency, thereby resulting in highly accurate productive efficiency scores. Thereafter, Simar and Wilson introduced a smooth bootstrapping procedure to accurately estimate the productive efficiency scores, and it has been applied internationally to measure the relative productive efficiency [23, 24].

Furthermore, the use of an output-orientated DEA, where DMUs are given a fixed quantity of resources (inputs) and asked to maximise output, is appropriate because the input of public hospitals is determined centrally by the Ministry of Health in China; hence, hospital managers have no control over the size of the hospitals they run [25]. The output-oriented DEA using a smooth bootstrapping procedure was adopted and operated on STATA 14.0.

\section{Stage two: bootstrapping truncated regression}

Given that the range of relative productive efficiency scores calculated by the DEA model falls between 0 and 1 , a Tobit and truncated regression model has traditionally been used to evaluate the factors affecting the productive efficiency $[10,16]$. However, Simar and Wilson argued that the use of a Tobit or truncated regression in a two-stage analysis is inappropriate based on two reasons: firstly, the productive efficiency scores estimated by DEA may be corrected with each other; thus, the results in the error term in these models are serially correlated and a standard inference is not valid. Secondly, in small samples, the explanatory variables used in regression analysis may be associated with the variables used for calculating productive efficiency scores in the DEA, thereby establishing a correlation between the error term 
and the explanatory variables [26, 27]. To avoid these controversial issues, we adopted bootstrapping truncated regression to explore the factors affecting the productive efficiency of MCHHs and performed it using STATA 14.0 following Simar and Wilson [24].

\section{Variables}

In our questionnaire, the input and output variables and several explanatory variables affecting efficiency were included. During the questionnaire design process, we implemented a two-round expert consultation based on literature review to determine which variables need to be investigated. After revising the questionnaire, we structured the final questionnaire (Additional file 1).

\section{Input and output variables}

Proper selection of input and output variables is crucial to accurately measure the relative productive efficiency of MCHHs. In the initial stage, we considered the number of open beds, the number of health workers, the total expenditure, the number of doctors, the number of nurses, the number of devices over 10,000 Chinese Yuan, the hospital area, the total fixed assets, the total service cost and the cost per visit as the input indicators based on previous studies $[10,13,28]$. The initial output variables selected included total revenue, income from medical services, the number of patient discharges, outpatient and emergency visits, the number of health examinations, average inpatient days and bed occupancy rate $[10,16,29]$.

To choose more representative ones from the aforementioned indicators, we firstly performed cluster analysis to address the overlap of the capability of variables in explaining the same portion of the outcomes. A correlation matrix was then extracted to identify and eliminate multicollinearity amongst the variables to help us construct a shortlist of the essential and representative variables. Finally, regression analysis was conducted to identify those inputs with high capability in explaining the variations in the selected outputs [30]. A coefficient of determination value of over 0.5 was considered a benchmark to select the final input and output variables. Table 1 shows the final list of the input and output variables.

\section{Explanatory variables affecting efficiency}

According to the literature, two types of factors have been proved to affect the productive efficiency of hospitals: the external and internal environmental factors of hospitals. External factors mainly include catchment population, distance, location (urban/rural), economic status, health insurance and occupancy rate. Hospital

Table 1 Inputs, outputs and explanatory variables and their explanation

\begin{tabular}{|c|c|c|}
\hline Category & Variable (Type of variable) & Explanation \\
\hline \multirow[t]{5}{*}{ Inputs } & Total expenditure (continuous) & $\begin{array}{l}\text { Capital consumption and defray in the process of service provision and other } \\
\text { activities, including healthcare, drug and medicine expenditures }\end{array}$ \\
\hline & Number of doctors (continuous) & Registered doctors at the end of year, excluding retirees and temporary staff \\
\hline & Number of nurses (continuous) & Registered nurses at the end of year, excluding retirees and temporary staff \\
\hline & Number of open beds (continuous) & Actual bed used at the end of the year (not registered beds) \\
\hline & $\begin{array}{l}\text { Number of devices over } 10,000 \text { Chinese } \\
\text { Yuan (continuous) }\end{array}$ & Sample hospital that owns medical devices worth more than 10,000 Yuan \\
\hline \multirow[t]{4}{*}{ Outputs } & Total revenue (continuous) & $\begin{array}{l}\text { Revenue gained from service provision and other activities, including healthcare } \\
\text { revenue, drug and medicine sales and financial subsidies }\end{array}$ \\
\hline & Number of patient discharges (continuous) & $\begin{array}{l}\text { Number of discharged patients after hospitalisation in sample hospitals at the end } \\
\text { of year }\end{array}$ \\
\hline & $\begin{array}{l}\text { Number of outpatient and emergency } \\
\text { visits (continuous) }\end{array}$ & $\begin{array}{l}\text { Number of patients coming for outpatient and emergency diagnostic services in } \\
\text { sample hospitals at the end of the year }\end{array}$ \\
\hline & Number of health examination (continuous) & $\begin{array}{l}\text { Number of health check ups for women and children conducted by the sample } \\
\text { hospital, including prenatal examination and postpartum visit }\end{array}$ \\
\hline \multirow[t]{6}{*}{ Factors } & Population (continuous) & Population in the region where the sample hospital is located \\
\hline & GDP per capita (continuous) & GDP per capita in the region where the sample hospital is located \\
\hline & Financial subsidy (continuous) & $\begin{array}{l}\text { Amount of financial subsidy from the government that hospitals can receive in a } \\
\text { financial year }\end{array}$ \\
\hline & Proportion of health professionals (continuous) & $\begin{array}{l}\text { As a percentage (\%) of all employees in the hospital. Health professionals include } \\
\text { doctors, nurses, pharmacists, inspection technicians and image technicians }\end{array}$ \\
\hline & $\begin{array}{l}\text { Number of health workers who received } \\
\text { job training (continuous) }\end{array}$ & $\begin{array}{l}\text { Number of health workers in sample hospitals who received related job training at } \\
\text { the end of the year }\end{array}$ \\
\hline & Average annual income of staff (continuous) & $\begin{array}{l}\text { Average annual income of employees in sample hospitals, including wages, bonuses } \\
\text { and subsidies }\end{array}$ \\
\hline
\end{tabular}


staff, educational status, income, average length of stay and hospital scale are frequently selected as the internal factors [10, 14-16, 31].

After reviewing the literature, we determined the candidate variables. We conducted a two-round expert consultation to discuss which explanatory variables should be selected from the candidate variables. Finally, population, GDP per capita in the sample region and financial subsidy from the government in a given financial year were selected as the external environmental factors. Internal environmental factors included the proportion of health professionals in the staff, the number of health workers who received job training and the average annual income of the staff (Table 1).

\section{Results}

Descriptive statistics of the input, output and explanatory variables

Table 2 describes the mean (SD) for the input, output and explanatory indicators of district- and county-level $\mathrm{MCHHs.} \mathrm{In} \mathrm{general,} \mathrm{no} \mathrm{remarkable} \mathrm{differences} \mathrm{were} \mathrm{ob-}$ served in terms of the outputs and inputs amongst these two types of MCHHs, although district-level hospitals had more visits and discharged patients compared with county-level hospitals. With regard to explanatory variables, a considerable difference was observed in terms of population and GDP per capita between the district- and county-level MCHHs. Additionally, the number of health workers who received relevant job training in the district-level hospitals was slightly higher than that in the county-level hospitals.
Bootstrapping bias-estimated productive efficiency scores Figures 1 and 2 present the distribution of the productive efficiency scores of district- and county-level $\mathrm{MCHHs}$ with and without bias corrections. Overall, the productive efficiency scores in the traditional DEA model were higher than those of the bias-corrected scores in bootstrapping DEA.

\section{Productive efficiency of district-level MCHHs}

After correcting bias via a bootstrapping DEA, the mean of TE, PTE and SE in district-level MCHHs was 0.7433, 0.8633 and 0.9335 , respectively. This result indicated that these $\mathrm{MCHHs}$ should, on average, increase their outputs by $13.67 \%$ with the same volume of inputs to achieve an effective level.

Figure 1 shows the distribution of TE, PTE and SE in 33 district-level MCHHs. All hospitals presented a TE and PTE scores less than 1, which meant that inefficiency was serious. Furthermore, the majority of the hospitals had a TE score of less than 0.9, and the hospitals with a PTE score between 0.80 and 0.99 accounted for approximately $85 \%$. For SE, the data indicated that more than a half of $\mathrm{MCHHs}$ (54.5\%) were operating under CRS, implying that these hospitals had no need to adjust their size to achieve optimal scale.

\section{Productive efficiency of county-level MCHHs}

The productive efficiency of county-level MCHHs was low with average bias-corrected TE and PTE scores of 0.5483 and 0.6081 , respectively, whilst the score of SE was 0.9329 . If the $\mathrm{MCHHs}$ in the sample were operating

Table 2 Statistical description for input, output and explanatory variables of district- and county-level MCHHs

\begin{tabular}{llll}
\hline Category & Variable & District level & County level \\
& & Mean \pm SD & Mean \pm SD \\
\hline Inputs & Total expenditure (10,000 RMB) & $9942.15 \pm 791.14$ & $8650.51 \pm 118.19$ \\
& Number of doctors & $18.64 \pm 10.97$ & $15.52 \pm 9.86$ \\
& Number of nurses & $14.18 \pm 7.08$ & $12.61 \pm 11.55$ \\
& Number of open beds & $31.81 \pm 9.84$ & $27.03 \pm 11.23$ \\
& Number of devices & $45.76 \pm 6.51$ & $31.90 \pm 11.40$ \\
Outputs & Total revenue (10,000 RMB) & $11,060.88 \pm 954.45$ & $9269.32 \pm 1063.23$ \\
& Number of patient discharges & $2190.44 \pm 687.19$ & $990.03 \pm 176.97$ \\
Factors & Number of outpatient and emergency visits & $27,175.58 \pm 5561.71$ & $18,558.79 \pm 2940.86$ \\
& Number of health examination & $13,756.32 \pm 7145.35$ & $13,087.94 \pm 3074.63$ \\
& Population & $444,967.42 \pm 197.25$ & $251,604 \pm 132.10$ \\
& GDP per capita (RMB) & $41,566.27 \pm 224.18$ & $26,179.51 \pm 145.50$ \\
& Financial subsidy (10,000 RMB) & $7021.21 \pm 454.33$ & $6864.05 \pm 767.72$ \\
& Proportion of health professionals (\%) & $42.63 \pm 3.71$ & $40.34 \pm 3.56$ \\
& Number of health workers who received job training & $35.24 \pm 2.50$ & $26.67 \pm 3.74$ \\
& Average annual income of staff (RMB) & $1313.87 \pm 126.74$ & $1106.42 \pm 162.56$ \\
\hline
\end{tabular}




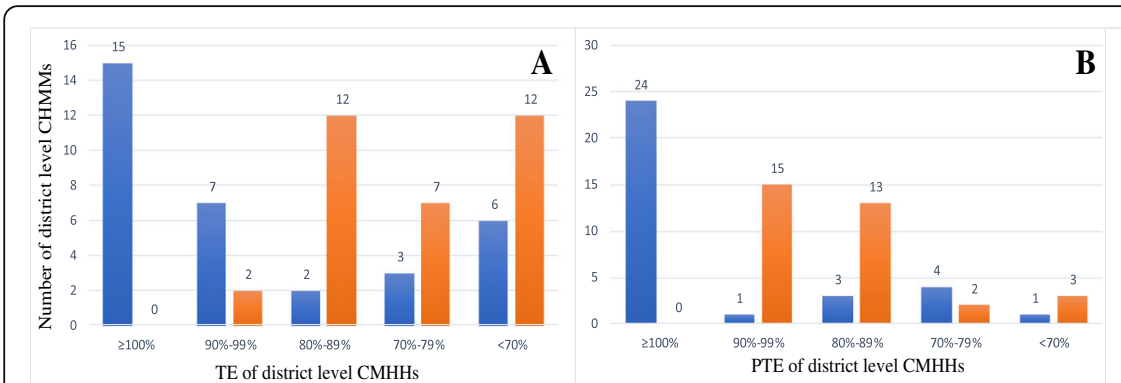

Fig. 1 The distribution of TE, PTE and SE in district level MCHHS

efficiently, then they should have produced $39.19 \%$ more outputs with the same volume of inputs.

As shown in Fig. 2, more than half of the MCHHs garnered TE and PTE scores less than 0.7, suggesting that these hospitals operated at low efficiency. Similar to district-level MCHHs, no hospitals obtained TE and PTE scores equal to 1 . SE was less of a problem as the remaining 29 hospitals (34.52\%) operated under CRS, and the scores of 33 hospitals (39.28\%) ranged from 90 to $99 \%$.

\section{Difference in productive efficiency between district- and county-level MCHHs}

As shown in Table 3, the differences in TE, PTE and SE between the district- and county-level MCHHs were identified via Student's $t$-test. The TE and PTE scores were significantly different $(p<0.001)$, in which the district-level MCHHs performed more efficiently than the county-level MCHHs. However, the difference was not statistically significant $(p=0.980)$ in terms of SE scores.

\section{Determinants of productive efficiency based on bootstrap truncated regression}

The bootstrap truncated regression model considered the TE score as the dependent variable and the external and internal hospital environmental factors as the independent variables. This model was established to analyse the effects of these factors.
As shown in Table 4, the proportion of health professionals (district level: $\beta=0.57,95 \% \quad \mathrm{CI}=0.30-0.85$; county level: $\beta=0.33,95 \% \mathrm{CI}=0.15-0.52$ ) had a positive association with efficiency scores. Similarly, the productive efficiency scores of district- $(\beta=0.67,95 \% \mathrm{CI}=0.26$ $1.08)$ and county-level $\mathrm{MCHHs}(\beta=0.34,95 \% \mathrm{CI}=0.14-$ 0.54 ) increased accordingly with the addition of the number of health workers who received relevant job training. Moreover, the amount of financial subsidies from the government $(\beta=0.07,95 \% \mathrm{CI}=0.05-0.09)$ was proportional to the productive efficiency of county-level MCHHs. With regard to the other factors, the results suggested that they had no significant relationship with the overall productive efficiency $(p>0.05)$.

\section{Discussion}

This study provides insights into the productive efficiency of district- and county-level MCHHs and their associated factors using the samples from Shanxi Province, China. Overall, these hospitals operated with low productive efficiency, but inefficiency in terms of SE was not obvious.

With respect to district-level $\mathrm{MCHHs}$, all units were found to be inefficient in terms of TE and PTE, and the TE scores for most hospitals (93.9\%) were less than 0.9. Thus, the overall technical inefficiency of district-level MCHHs in Shanxi Province is serious but with huge potential for improvement. In other words, the resources invested to $\mathrm{MCHHs}$ at their current size are not fully

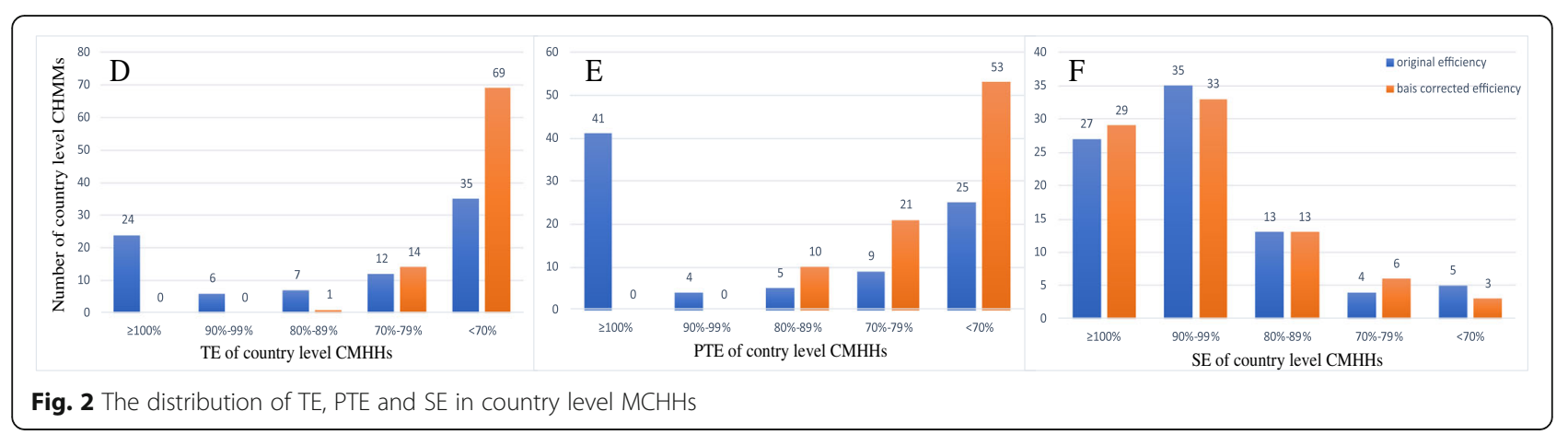


Table 3 Comparison of difference in TE, PTE and SE scores between district- and county-level MCHHs

\begin{tabular}{llllll}
\hline & Hospital & $N$ & Mean & S.D. & $P$ \\
\hline TE & District level & 33 & 0.7433 & 0.1327 & $<0.001$ \\
& County level & 84 & 0.5483 & 0.1513 & \\
PTE & District level & 33 & 0.8633 & 0.0777 & $<0.001$ \\
& County level & 84 & 0.6081 & 0.1643 & \\
SE & District level & 33 & 0.9335 & 0.1350 & 0.980 \\
& County level & 84 & 0.9329 & 0.1055 & \\
\hline
\end{tabular}

utilised, and their output is insufficient [10, 25]. Similarly, PTE was a widespread problem, that is, the capacity of management and technology in the district-level $\mathrm{MCHHs}$ was rather low. Although more than half of the hospitals performed under CRS, the scales of operation of these inefficient hospitals should be adjusted.

The inefficiency of the county-level MCHHs presented in this study was more severe than that of the district-level MCHHs. On the one hand, all hospitals did not achieve an optimal output value, similar to the situation of the districtlevel MCHHs. On the other hand, an average of $45.17 \%$ of the health resources of the county-level MCHHS were wasted, and the majority (80\%) performed with a productive efficiency score less than 0.7 . These findings suggest that productive efficiency can be improved by optimal utilisation of the available health resources of primary-level MCHHs.

These results were in agreement with those of Athanassopoulos [32], who pointed out that district-level MCHHs have a higher TE and PTE compared with county-level MCHHs. A possible explanation is that the huge disparity in terms of economic status between the rural and urban areas in China results in uneven distribution of health resources, especially in terms of the professional health workforce. Under such a circumstance, district-level MCHHs in urban regions obtain more technical and financial support than county-level $\mathrm{MCHHs}$, allowing the former to operate efficiently [33].
Regression coefficients of the proportion of health professionals and the number of health workers who received job training indicated that these two variables had a significant positive relationship with the overall technical efficiency of district- and county-level MCHHs. These results were consistent with those of other studies. Indeed, health workers, as the core health resource in hospitals, have a direct effect on the quantity and quality of health services and substantially contribute to outputs [11, 34]. However, most skilled health technicians are unwilling to work in primary healthcare sectors due to low income and high-pressure working conditions $[6,7,10]$. These factors explain why these hospitals fail to attract and retain patients, thereby further reducing their productive efficiency. Thus, introducing qualified personnel from the outside and training internal personnel to improve their skills are effective measures to enhance the service capabilities and optimise the outputs of primary-level MCHHs.

With regard to the external environmental factors, the regression model showed a statistically significant and positive relationship between financial subsidy from the government and productive efficiency of county-level MCHHs. As non-profit public hospitals in China, county-level MCHHs provide affordable basic medical services for low-income rural residents and undertake public health projects, such as vaccination for children and postpartum visit, free of charge. The financial subsidy from the government is usually regarded as the main source of hospital income (the proportion of income from financial subsidy to total income, on average, reached $86 \%$ in our study). However, in poor counties, $\mathrm{MCHHs}$ are unable to receive adequate financial support from their governments. Under such conditions, countylevel hospitals lack funds to provide free $\mathrm{MCHC}$, thereby negatively affecting their outputs $[35,36]$.

Notably, the coefficient of GDP per capital had no significant effect on efficiency scores. This finding was

Table 4 Estimation results from bootstrap truncated regressions

\begin{tabular}{|c|c|c|c|c|}
\hline \multirow[t]{2}{*}{ Dependent variable } & \multicolumn{2}{|c|}{ District-level MCHHs } & \multicolumn{2}{|c|}{ County-level MCHHs } \\
\hline & $\beta$ & $95 \% \mathrm{Cl}$ & $\beta$ & $95 \% \mathrm{Cl}$ \\
\hline Population (in logs) & 0.06 & $(-0.09,0.21)$ & 0.03 & $(-0.03,0.09)$ \\
\hline GDP per capita (in logs) & -0.05 & $(-0.15,0.03)$ & -0.03 & $(-0.09,0.01)$ \\
\hline Financial subsidy (in logs) & -0.02 & $(-0.25,0.20)$ & $0.07^{* *}$ & $(0.05,0.09)$ \\
\hline Health professionals & $0.57^{* *}$ & $(0.30,0.85)$ & $0.33^{* *}$ & $(0.15,0.52)$ \\
\hline Health workers who received job training & $0.67^{*}$ & $(0.26,1.08)$ & $0.34^{*}$ & $(0.14,0.54)$ \\
\hline Average annual income of staff (in logs) & 0.02 & $(-0.18,0.23)$ & 0.01 & $(-0.01,0.04)$ \\
\hline Sigma & 0.06 & & 0.05 & \\
\hline Log likelihood & 42.69 & & 119.27 & \\
\hline Wald $\times 2$ & 51.89 & & 512.30 & \\
\hline
\end{tabular}

*: $p<0.05 ; * *: p<0.001 ; 2000$ bootstrapping replications were used 
inconsistent with that of other studies [10, 37]. A possible explanation is the huge disparity in the distribution of health resources between primary health institutions and tertiary hospitals. This circumstance forces patients to visit higher level hospitals to receive better quality of services in China [38]. Accordingly, most women and children tend to choose provincial or municipal MCHHs. This tendency may result in a reduced variation in outputs, such as in terms of the number of outpatients and inpatients, amongst developed and underdeveloped areas. Therefore, this variable is not sensitive for productive efficiency in the model.

Several limitations in our study should be mentioned. Firstly, the sample size of 33 district-level MCHHs is relatively small, although we adopted a bootstrapping DEA to correct bias. Secondly, factoring only six independent variables representing external and internal hospital environmental factors is insufficient to explain the variation in productive efficiency scores in bootstrap truncated regressions due to the inaccessibility of other data. Thirdly, given the lack of information about the case mix of each hospital or patient outcome, variables related to service quality (such as risk-adjusted mortality) were not included in the output when we created the DEA model. Therefore, further research should consider the quality of care whenever data are available.

Despite the aforementioned limitations, this study is still considered a laudable attempt to explore the productive efficiency of primary-level $\mathrm{MCHHs}$ and identify their associated multi-faceted factors, especially after the implementation of China's new round of health care system reforms.

\section{Conclusions}

Overall, the efficiency of district- and county-level $\mathrm{MCHHs}$ is rather low and needs to be improved, especially in terms of TE and PTE. The factors that are significantly associated with productive efficiency have several implications. Firstly, introducing additional medical personnel and ensuring the stability of the workforce should be prioritised. Secondly, vocational training and continuing education for health care technicians must be provided to enhance their medical skills and improve the efficiency of primary-level MCHHs. Thirdly, the government needs to provide sufficient financial subsidy for primary-level MCHHs to compensate for service costs.

\section{Supplementary information}

Supplementary information accompanies this paper at https://doi.org/10. 1186/s12913-020-5032-y.

Additional file 1. Questionnaire

\section{Abbreviations}

CRS: Constant return to scale; DEA: Data envelopment analysis;

DMU: Decision-making unit; DRS: Decreasing returns to scale; IRS: Increasing returns to scale; MCHC: Maternal and child health care; MCHHs: Maternal and child health hospitals; MDGs: Millennium Development Goals; PTE: Pure technical efficiency; SE: Scale efficiency; TE: Technical efficiency; VRS: Variable return to scale

\section{Acknowledgements}

Not applicable.

\section{Authors' contributions}

All authors made significant contributions to this study. TZ conceptualised the study. WL collected and analysed the data. TZ wrote the first draft of the manuscript. WL and HT interpreted the results and revised the manuscript. HT critically commented on the paper. The final version submitted for publication was read and approved by all authors.

\section{Funding}

This study was supported by the National Natural Science Foundation of China (NO. 71774061).

\section{Availability of data and materials}

The data sets analysed during this study are available from the corresponding author upon reasonable request.

Ethics approval and consent to participate

Not Applicable.

\section{Consent for publication}

Not applicable.

\section{Competing interests}

The authors declare that they have no competing interests.

Received: 22 August 2019 Accepted: 24 February 2020

Published online: 06 March 2020

References

1. Lawn JE, Tinker A, Munjanja SP, Cousens S. Where is maternal and child health now? Lancet. 2006;368(9546):1474-7.

2. Guo Y, Bai J, Na H. The history of China's maternal and child health care development. Semin Fetal Neonatal Med. 2015;20(5):309-14.

3. United Nations Department of Political Affairs (UNDPA). United Nations Millennium Declaration. The Wiley-Blackwell Encyclopedia of Globalization. 2000;20(1):182-221.

4. WHO. Health in 2015, from MDGs, Millennium Development Goals to SDGs, Sustainable Development Goals. Geneva: World Health Organisation; 2015.

5. China women and children development program. http://www.gov.cn/ ztzl/61/content_627720.htm. Accessed 28 May 2007.

6. Zeng Y, Hesketh T. The effects of China's universal two-child policy. Lancet. 2016;388(10054):1930-8.

7. Li Y, Zhang Y, Fang S, Liu S, Liu X, Li M, Liang H, Fu H. Analysis of inequality in maternal and child health outcomes and mortality from 2000 to 2013 in China. Int J Equity Health. 2017;16(1):66.

8. Strand MA, Fischer PR. An appraisal of China's progress toward the Millennium Development Goals as they relate to children. Ann Trop Paediatr. 2013;34(3):156-64.

9. Lozano R, Wang H, Foreman KJ, Rajaratnam JK, Naghavi M, Marcus JR, Dwyer-Lindgren L, Lofgren KT, Phillips D, Atkinson C, Lopez AD. Progress towards Millennium Development Goals 4 and 5 on maternal and child mortality: an updated systematic analysis. Lancet. 2016;378(9797):1139-65.

10. Xuan W, Luo H, Qin X, Feng J, Gao H, Feng Q. Evaluation of performance and impacts of maternal and child health hospital services using Data Envelopment Analysis in Guangxi Zhuang Autonomous Region, China: a comparison study among poverty and non-poverty county level hospitals. Int J Equity Health. 2016;15(1):131.

11. Ren Z, Song P, Theodoratou E, Guo S, An L. China's human resources for maternal and child health: a national sampling survey. BMC Health Serv Res. 2015;15(1):561.

12. White paper on medical and health services in China http://www.chinadaily. com.cn/china/2012-12/27/content_16059095_3.htm. Accessed 27 Dec 2012. 
13. Yan XU, Shen ZH, Wang XF. Evaluation on the efficiency of country levels of maternity and child care institutions in Jiangsu by DEA. Matern Child Health Care China. 2013;49(79):9039-41.

14. Ravangard R, Hatam N, Teimourizad A, Jafari A. Factors affecting the technical efficiency of health systems: a case study of Economic Cooperation Organization (ECO) countries (2004-10). Int J Health Policy Manag. 2014;3(2):63

15. Kiadaliri AA, Jafari M, Gerdtham UG. Frontier-based techniques in measuring hospital efficiency in Iran: a systematic review and meta-regression analysis. BMC Health Serv Res. 2013;13(1):312.

16. Mujasi PN, Asbu EZ, Puig-Junoy J. How efficient are referral hospitals in Uganda? A data envelopment analysis and tobit regression approach. BMC Health Serv Res. 2016;16(1):1-14.

17. Charnes A, Cooper WW, Lewin AY, Seiford LM. Data envelopment analysis theory, methodology and applications. J Oper Res Soc. 1997:48(3):332-3.

18. Banker RD, Charnes A, Cooper WW. Some models for estimating technical and scale inefficiencies in data envelopment analysis. Manag Sci. 1984;30(9): 1078-92.

19. Cheng Z, Tao H, Cai M, Lin H, Lin X, Shu Q, Zhang RN. Technical efficiency and productivity of Chinese county hospitals: an exploratory study in Henan province, China. BMJ Open. 2015;5(9):e007267.

20. Charnes A, Cooper WW, Rhodes E. Measuring the efficiency of decision making units. Eur J Oper Res. 1978;2(6):429-44.

21. Kounetas K, Papathanassopoulos F. How efficient are Greek hospitals? A case study using a double bootstrap; DEA approach. Eur J Health Econ. 2013;14(6):979-94.

22. Simar L, Wilson PW. Sensitivity analysis of efficiency scores: how to bootstrap in nonparametric frontier models. Manag Sci. 1998;44(1):49-61.

23. Simar LO, Wilson PW. A general methodology for bootstrapping in nonparametric frontier models. J Appl Stat. 2000;27(6):779-802.

24. Simar L, Wilson PW. Estimation and inference in two-stage, semi-parametric models of production processes. J Econ. 2007;136(1):31-64

25. Cheng Z, Cai M, Tao H, He Z, Lin X, Lin H, Zuo Y. Efficiency and productivity measurement of rural township hospitals in China: a bootstrapping data envelopment analysis. BMJ Open. 2016;6(11):e011911.

26. Meschi M, Pierleoni MR, Gori S. Advanced semi-parametric and parametric methods to assess efficiency in the postal sector. Heidelberg: Springer International Publishing; 2015.

27. Simar L, Wilson PW. Two-stage DEA: caveat emptor. J Prod Anal. 2011;36(2): 205-18.

28. Li H, Dong S, Liu T. Relative efficiency and productivity: a preliminary exploration of public hospitals in Beijing, China. BMC Health Sen Res. 2014;14(1):158.

29. Hao L, Siping D. Measuring and benchmarking technical efficiency of public hospitals in Tianjin, China: a bootstrap-data envelopment analysis approach. Inquiry. 2015;52(52):1-5.

30. Xu X, Zhou L, Antwi HA, Chen X. Evaluation of health resource utilization efficiency in community health centers of Jiangsu Province, China. Hum Resour Health. 2018;16(1):13.

31. Zere E, Mcintyre D, Addison T. Technical efficiency and productivity of public sector hospitals in three South African provinces. S Afr J Econ. 2010; 69(2):336-58.

32. Athanassopoulos A, Gounaris C. Assessing the technical and allocative efficiency of hospital operations in Greece and its resource allocation implications. Eur J Oper Res. 2001;133(2):416-31.

33. Weng $Z$, Gong Y. Analysis efficiency of hospital in urban and rural areas. Chin Health Resour. 2002;5(3):124-6.

34. Cogin JA, Ju LN, Lee I. Controlling healthcare professionals: how human resource management influences job attitudes and operational efficiency. Hum Resour Health. 2016;14(1):55.

35. Zhou H, Zhao CX, Wang XL, Xv YC, Shi L, Wang Y. Effectiveness of an intervention on uptake of maternal care in four counties in Ningxia, China. Trop Med Int Health. 2012;17(12):1441-8.

36. Liang SL, Wang X, Gao HD. Analysis on economic operational status of maternal and child health care hospitals at county level in Guangxi from 2008 to 2010. Matern Child Health Care China. 2014;29(33):5364-6.

37. Chu K, Zhang N, Chen Z. The efficiency and its determinants for China's medical care system: some policy implications for Northeast Asia. Sustainability. 2015;7(10):14092-111.

38. Zhang $T, X u Y$, Ren J. Inequality in the distribution of health resources and health services in China: hospitals versus primary care institutions. Int Equity Health. 2017;16:42-50.

\section{Publisher's Note}

Springer Nature remains neutral with regard to jurisdictional claims in published maps and institutional affiliations.
Ready to submit your research? Choose BMC and benefit from:

- fast, convenient online submission

- thorough peer review by experienced researchers in your field

- rapid publication on acceptance

- support for research data, including large and complex data types

- gold Open Access which fosters wider collaboration and increased citations

- maximum visibility for your research: over $100 \mathrm{M}$ website views per year

At BMC, research is always in progress.

Learn more biomedcentral.com/submissions 